\title{
Use of an Object-Oriented System for Optimizing Life Cycle Embodied Energy and Life Cycle Material Cost of Shopping Centres
}

\author{
K K Weththasinghe ${ }^{1}$, André Stephan ${ }^{2}$, Valerie Francis ${ }^{3}$ and Piyush Tiwari ${ }^{4}$ \\ 1,2,3,4 The University of Melbourne, Parkville, VIC 3010 Australia \\ kweththasing@student.unimelb.edu.au
}

\begin{abstract}
Shopping centres are an integral part and a critical component of urban cities in most economies. Typically, the shorter refurbishment cycle and frequent tenant replacements in shopping centres cause excessive use of building materials over its service life. This drastic use of resources, consequently, increase life cycle embodied energy (LCEE) and life cycle material cost (LCMC) of shopping centres. Therefore, careful selection of materials is vital to reduce the negative environmental impacts and material costs. Current research on the implications of material choices on LCEE and LCMC of shopping centres are insubstantial and decisions makers are left with limited information to make better selections. Therefore, selection of energy efficient, cost-effective and environmentally responsive materials and assemblies has been a critical process for the professionals who are involved in decision-making. This paper proposes the use of object-oriented programming (OOP) to develop a mathematical model to develop combinations of building assemblies with minimum LCEE and LCMC of shopping centres through material selection. The model is based for sub-regional shopping centres in Australia, yet can be applied for any similar property type with modifications to databases and model architecture. However, scope of this paper is limited to the development of model architecture with detailed explanations on databases and computing core development. Even though, the detailed presentation of development of OOP structure provides proper insight to the mathematical core for future application.
\end{abstract}

Keywords: Life Cycle Embodied Energy (LCEE), Life Cycle Material Cost (LCMC), Material Selection.

\section{Introduction}

Shopping centres are the largest component of the retail property sector and an important aspect of modern cities [1]. They are inevitably one of the major energy and resource users in the built environment over the life cycle [2, 3]. The extended opening hours, high ceilings and excessive use of illuminations and heating and cooling cause the heaps in operational energy use over life cycle while shorter refurbishment cycle and frequent tenant replacements cause the excessive embodied energy and material use $[3,4]$ in shopping centres. The necessity to maintain trendy aesthetics in 
shopping centres require incessant maintenance and upgrades [5]. Additionally, tenant leases cause frequent material replacements depending on the lease periods and tenant replacements [6, 7]. Hence, materials used in shopping centres serve a shorter life before becoming obsolete [8] resulting in increased life cycle embodied energy (LCEE) in shopping centres when compared to other residential and commercial buildings [9]. Furthermore, this sustained use and disposal of building materials over the life cycle ultimately result in an elevated life cycle material cost (LCMC) [10]. Therefore, material selection for shopping centres needs to be more thorough and observant to mitigate negative environmental impacts of increased LCEE and to reduce LCMC. Hence, this paper aims to propose an approach to identify combinations of building materials and assemblies with optimum LCEE and LCMC for shopping centre development in Australia.

\section{$2 \quad$ Literature review}

Shopping centres are major energy and resource users over their life cycle [11]. Being community places, shopping centres use large amounts of energy to maintain the good and comfort visual [12]. They require continuous maintenance and refurbishments over the years to attract and sustain foot traffic and tenants [13] (refurbishment: any 'remodeling, refashioning and general renovation of a building, site, product or infrastructure'[14]). Tenants of shopping centers are often required to refurbish the premises during or at the end of their leases [9, 15]. According to the Retail Leases Act 2003 , a tenant entering a new lease for a retail shop has the right to a minimum tenancy period of up to five years (which can be renewed at the end of lease). Hence refurbishments can occur during the five-year lease period and when it is terminated and beginning of a new tenant. This is comparable to the findings by [9] who stated that refurbishment frequency of retail shops is every 2 to 10 years. Empirical findings through interviews with sub-regional shopping centre managers in Australia also solidifies the findings of literature on refurbishment frequency.

The shorter refurbishment cycle and frequent tenant replacements inevitably cause excessive building material usage in shopping centres [16]. Building materials are replaced long before reaching the end of their expected service lives due to economic, functional or social obsolescence during refurbishments [8]. Hence, the recurrent embodied energy (the energy required for the maintenance and replacement of building materials or systems during the building useful life [17]) becomes vital in shopping centres, notably compared to other commercial and residential building types [9]. Consequently, LCEE (combination of initial and recurrent embodied energy and demolition energy [18]) of shopping centres become immense [9, 11]. Hence, careful attention needs to be given to material selection process of shopping centres [19] to reduce LCEE.

Since the evolving concern on sustainability in built environment has already made a significant impact in shopping centre development and redevelopments in terms of operation energy use, next is to address the embodied energy issue [16]. However, it is important to maintain a trade-off between minimization of operational and embod- 
ied energy since the extreme measures to minimize one can lead to a significant escalation in the other. Therefore, selection of environmentally responsive building materials is challenging not only due to prior reasons but also due to financial constraints [20]. Typically, initial cost of materials and assemblies can make up to $20 \%$ to $30 \%$ of the total project cost [21]. Also, environmentally responsible, innovative building materials are alleged to be more expensive than conventional building materials [8]. Additionally, frequent material replacements in shopping centres cause an enormous cost over the life cycle [22]. Therefore, minimizing LCMC (total of capital, maintenance and refurbishment and disposal or recycling costs) of shopping centres also becomes vital.

Research has identified cost as one of the main barriers for the selection of materials with improved environmental performances [23]. Also, literature has acknowledged that material selection has a close relationship between embodied energy and cost of buildings $[14,15,24]$. However, the findings of a few research can only be used within a limited boundary due to the lack of comprehensiveness of the approach used to generate life cycle inventory data used and the scope of research [25]. Furthermore, many researches in the area of embodied energy analysis and cost of materials are concentrated around residential and commercial office buildings [23, 25]. Only a limited number of studies are engaged in retail property and embodied energy $[9,12]$ but none of them are focused on LCEE and LCMC in shopping centres. Hence, the knowledge on availability of building materials with lower embodied energy with minimum LCMC (with minimum negative impact to life cycle operational energy use in the building) for shopping centre construction is lacking.

Several models have been developed to assist in the process of selection of building materials, engaging different optimization methods [15], analytic hierarchy processes [24] and computer aided software tools [26]. However, the existing models are not precisely focused on the unique nature of shopping centres, and their exceptional material replacement frequencies. Hence, a mathematical model which incorporates the unique features of shopping centres is required to facilitate the selection of combinations of materials and assemblies with minimum LCEE and LCMC. This research niche is therefore addressed in this paper.

Accordingly, the research problem identified can be expressed in the form of a programming problem as follows;

Minimize $f(x)$; subject to $g(x)$ and $h(x)$, where $(x)$ is a vector of $n$ real value design variables which will be alternative building material and assembly combinations and $f$ is the cost function also known as the objective function. $g(x)$ and $h(x)$ are the inequality and equality constraints. The study aims to achieve three objective functions as;

Minimize LCEE $(x)$

Minimize LCMC ( $x$ )

Minimize LCEE \& LCMC $(x)$ 
The study follows a case study research method with a mathematical modelling process to achieve set forth aim and objectives. The mathematical model is developed for an archetypal single-story sub-regional shopping centre in Australia. Sub-regional shopping centre is selected as the base type for the model since it dominates Australian shopping centre industry in terms of investments [27], GLA (gross lettable area) and with a three-year pipeline of planned developments and redevelopments till 2021 $[21,28]$. Case studies are carried out to observe and identify the most representative single story sub-regional shopping centre which is selected as the base case for archetypal centre design (Since more than $75 \%$ of sub-regional shopping centres in Australia are single story buildings the archetypal is designed following the majority [21, 28]). Three different scenarios with different tenant mixes and GLAR (gross lettable area retail) are tested. The results are analyzed to examine the relationships between material selection and LCEE and LCMC and to identify combinations of building materials and assemblies with optimum LCEE and LCMC for sub-regional shopping centres in Australia.

This paper presents the knowledge on the development of mathematical model and databases which can be used as an archetype to resolve similar problems in the built environment.

\section{Object-Oriented Programming (OOP) as a method}

Development of any mathematical model require automation of complex systems and rigorous calculation processes [29]. LCEE and LCMC calculation of sub-regional shopping centres is a complex task since they are massive building projects with a wide range of building elements and assemblies used. The process of calculations requires different data sets of materials, assemblies, bills of quantities of different types of shops and many other and demanding matrix calculations (further explained in 2.1). Therefore, the model developed needs to accomplish the requirements and specifications to achieve the set forth objectives. One of the main requirements of the model is to assess and compare different scenarios of sub-regional shopping centres at a reduced run time. Further, the model architecture needs to be resilient yet flexible. OOP provides solutions to all these requirements.

OOP is a programming paradigm organized around "objects" and data [29, 30]. An object includes a set of data with associated behaviors. Objects with different attributes and methods are classified under different classes. A "class" is basically a blueprint of an object. In other words, the classes describe the objects with attributes, methods and variables. Different types of objects can have different classes [30]. The study defines four class modules as Materials, Assemblies, Shop, and ShoppingCentre. Each class instance can have attributes attached to it for maintaining its state. Class instances can also have methods (defined by its class) for modifying its state [31]. For instance, Shop class has parameters as length, width, height, etc. and the method get_quantity_gfa. Since OOP provides a flexible architecture, the attributes or the parameters of classes can be modified without changing the calculation algorithms. Hence, different instances of a class can be assessed based on their attributes. 
Furthermore, additions of new methods to a class often does not affect other methods in the class. Thus, updates can be performed with minor impact on the entire model, because of the modular structure [32]. Consequently, OOP is selected as the programming paradigm to develop the model architecture.

To develop the mathematical model, a software programming is required. This study uses Python ${ }^{\mathrm{TM}} 3.7$ as the programming language since it is free and opensource [33]. It also provides a large array of libraries including classes and functions which are designed specially to tackle specific aspects of programming [31]. Different Python based modules are available for free for database generation, to develop matrices and other numerical operations and to generate graphs and charts. OOP in Python is proven to be an efficient method for real-world applications [29]. Hence, the programming language chosen to develop the model, is Python.

\subsection{Model architecture}

A general software tool consists of three main compartments as graphical user interface (GUI), computing core and the databases. However, at this stage the research is limited to developing the computing core and the databases only. The computing core is the model architecture containing all the classes with defined attributes and methods for all related calculations to quantify LCEE and LCMC of the shopping centre for different assembly combinations. The data required to execute the methods are mostly extracted from the databases. The databases are the data sets of materials, assemblies, shops and shopping centres which provide attribute values to the classes.

\subsection{Classes and databases}

To understand the development of classes, the reader should be familiar with the hierarchy of different levels. Fig .1. demonstrates the sequence of classes in the computing core.

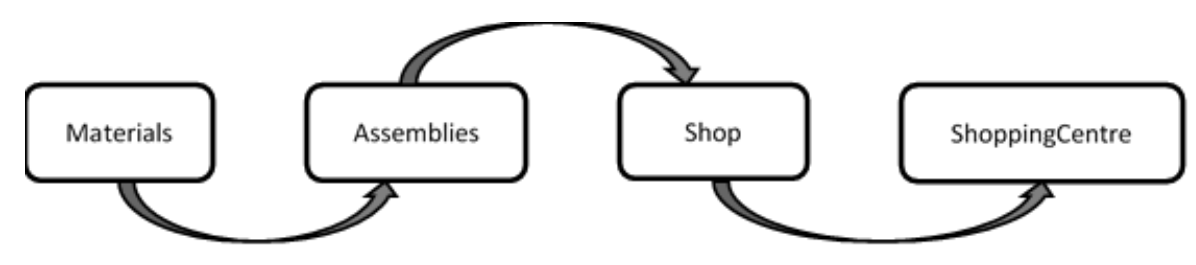

Fig. 1. Sequence of levels of classes and databases

Materials class imports data from materials database. Materials database provides material details under fields of material_id (unique for each material), material_name, material_type, material_unit $\left(\mathrm{m}, \mathrm{m}^{2}, \mathrm{~m}^{3}\right.$, $\mathrm{t}$, etc.) material_eec, material_unit_price, etc. Material instances are created at Materials class using the database. Assemblies database is created to store different assemblies which can be constructed using the materials objects. Assemblies database delivers datasets of assemblies under different 
fields such as assembly_id, assembly_type (assemblies are categorized under 13 assembly_types as foundation, column, internal_wall, etc. based on AIQS building elements and sub-elements [34]), assembly_unit $\left(\mathrm{m}, \mathrm{m}^{2}, \mathrm{~m}^{3}\right)$, etc. Further it contains details of quantities of each material in a unit of assembly and respective material_id which will be used to determine assembly embodied energy coefficient (eec) and unit price. For instance, consider M7 and M30 are respective material_id of 12mm rebars and 20Mpa concrete.

Table 1. Sample assembly

\begin{tabular}{llll}
\hline Assembly_id & Assembly_type & Assembly_name & Assembly_unit \\
\hline BM01 & beam & $300 * 300$ concrete beam & $\mathrm{m}$ \\
\hline
\end{tabular}

To build $1 \mathrm{~m}$ of assembly_id BM01, following quantities of M7 and M30 are required.

$$
\text { M7 - } 0.001(\mathrm{t}) \text { and M30 - } 0.09(\mathrm{~m} 3)
$$

Since materials instances delivers material_eec and material_unit_price, to determine assembly_eec and assembly_unit_price instances of Assemblies class access the material objects created at Materials class. This process is methodologically formed in Assemblies class to create assembly objects with required steps and calculations. Shop class is the largest class in the model with several methods to perform required calculations to gradually determine shop_lcee, shop_lcmc and develop shop_boq. Unlike previous classes Shop class import data from two different databases: shops catalogue database and shops database. Shops catalogue database provides data on different types of shops in the shopping centre under 16 categories (e.g. clothing, food_supplies, health_\&_beauty, etc.[27, 35]). Each shop type is given a unique id same as previous and characteristics are defined in different fields. Also, default assemblies for each assembly_type are defined for each shop_type.

Table 2. Sample shop_type

\begin{tabular}{lllll}
\hline Shop_type_id & beam & ceiling_finish & column & door \\
\hline CL_01_RF_5 & BM04 & CF01 & CL04 & DR01 \\
\hline
\end{tabular}

Shops database defines the geometry of different shops in the archetypal shopping centre. Every shop has a shop_type as defined in shops catalogue database and attribute values of length, width, height and span. This format of database allows the researcher to develop parametric shop designs following the shoe-box concept. Working with parametric designs provide flexibility to the shopping centre design and thus allow for future modifications to the model. The geometries defined for each shop are used in Shop class to generate BOQ (bills of quantities) with automated calculations of quantities of building assembly types. ShoppingCentre class defines the three different scenarios of archetypal shopping centre (with different tenant mixes).

Constraints to the model are also provided as databases. Assembly compatibility matrix (assembly compatibility with each other is demonstrated with TRUE and FALSE operators) and Assembly shop compatibility matrix (compatibility of assemblies with each shop type) are the two main constraint databases. The model uses 
these classes and databases to gradually determine the combinations of assemblies for each assembly type with minimum LCEE and LCMC for sub-regional shopping centres in Australia. The following section provides a demonstration of how these classes are utilized to determine the combinations of assemblies with minimum LCEE.

\subsection{Assessment of LCEE}

Aim of this study is to identify combinations of building assemblies with minimum LCEE and LCMC for sub-regional shopping centre construction in Australia using OOP model. Fig. 2. demonstrates the flowchart to assess the LCEE.

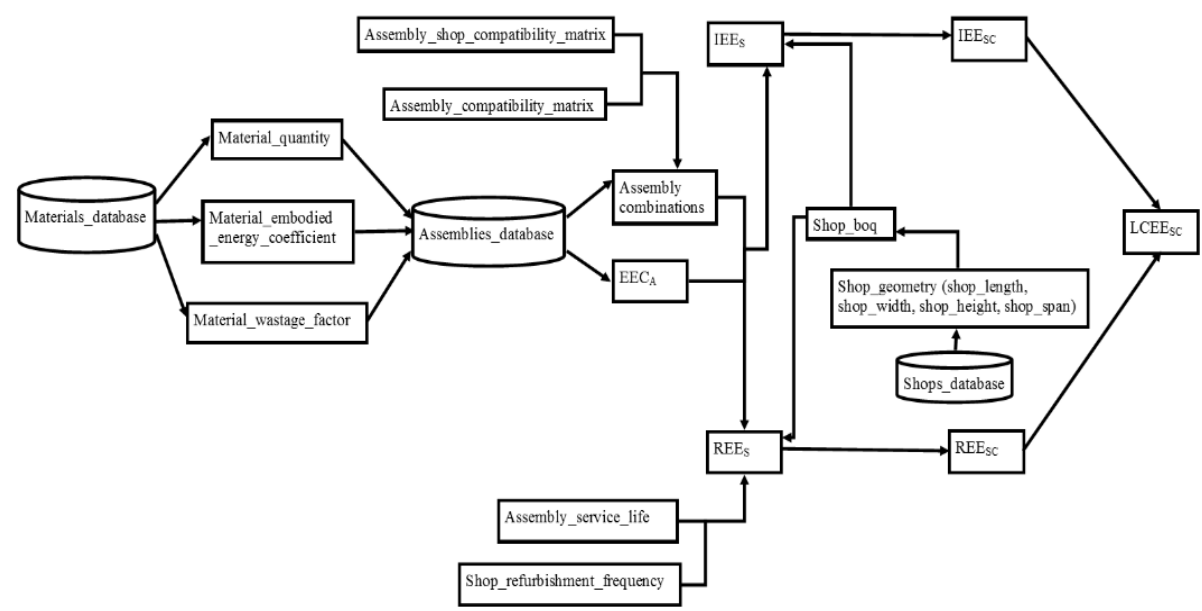

Fig. 2. LCEE assessment flow chart

In Fig. 2.,

$\mathrm{EEC}_{\mathrm{A}}=$ Embodied energy coefficient of an assembly

IEE $_{S}=$ Initial embodied energy of a shop

REE $_{S}=$ Recurrent embodied energy of a shop

IEE $_{S C}=$ Initial embodied energy of shopping centre

REE $_{\text {SC }}=$ Recurrent embodied energy of shopping centre

LCEE $_{S C}=$ Life cycle embodied energy of shopping centre

At Shop level assembly combinations are generated for different shop types using assemblies database, shop database, shops_catalogue and compatibility matrices. Shops of different assembly combinations are then combined to develop alternatives of the three shopping centre scenarios. The LCEE of every alternative shopping centre is quantified following the above process. LCEE is defined as the combination of IEE (initial embodied energy) and REE (recurrent embodied energy) of the shopping centre. The study neglects the impacts of demolition energy towards LCEE since literature analysis finds it negligible when life cycle approach is considered [3], [14], [19], [30]. As shown in Fig. 2. the IEE of the centre is the sum of IEE of all the shops in the centre which in turn, is the sum of the IEE of its assemblies, itself the sum of the IEE 
of constituting materials. Following equations denote IEE calculation at different levels.

$I E E_{s c}=\sum_{s} \sum_{a} \sum_{m} E E C_{m} \times Q_{m, a, s}$

$I E E_{S C} \quad=$ IEE of shopping centre

$E E C_{m}=$ Embodied energy coefficient of material $\mathrm{m}$

$Q_{m, a, s}=$ Quantity of material $\mathrm{m}$ in assembly a in shop $\mathrm{s}$

The non-material energy inputs at the construction stage are added as per Equation 5. This includes inputs associated with the financial, communication, marketing and other service sectors, which are considered as further sideway inputs [25]. $Q_{M, A, S}$ is also modified by incorporating the wastage factor of material.

$I E E_{s c}=\sum_{s} \sum_{a} \sum_{m}\left(E E C_{m} \times Q_{m, a, s} \times W F_{m}\right)+\left[T E R R E B S-\sum_{m=1}^{M}\left(T E R_{m}\right)\right] \times C_{s c}$

$W F_{m} \quad=$ Material wastage factor

TERREBS = Total energy requirement of the retail building sector (GJ per currency unit)

$T E R_{m} \quad=$ Total energy requirement of the input-output pathway representing material $\mathrm{m}$ (GJ per currency unit)

$C_{s c} \quad=$ Total cost of the shopping centre

The REE of shopping centres can be calculated using the following Equation 6 developed by [36].

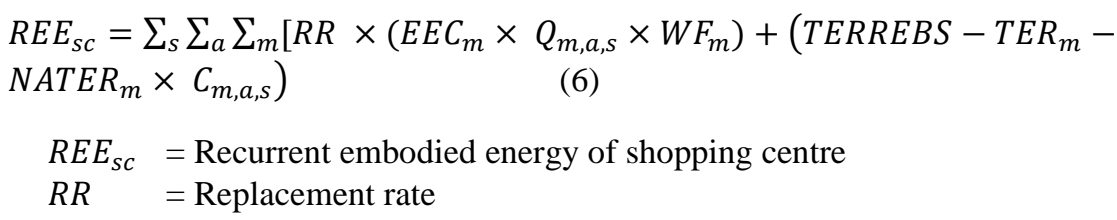

$N A T E R_{m}=$ The total energy requirement of all input-output pathways not associated with the installation or production process of material $\mathrm{m}$ being replaced (GJ per currency unit)

$C_{m, a, s}=$ Cost of material $\mathrm{m}$ in assembly a in shop s

In Equation 7, RR can be characterized in the following manner.

$R R=\left\{\left[\frac{P O A_{a, s}}{S L_{m, a, s}}-1\right\rceil \Leftrightarrow\left\lceil\frac{P O A_{a, s}}{S L_{m, a, s}}-1\right\rceil \leq R F_{s}\right\} ;\left\{R F \Leftrightarrow\left\lceil\frac{P O A_{a, s}}{S L_{m, a, s}}-1\right\rceil \geq R F_{s}\right\}$

$P O A_{a, s}=$ Period of analysis of assembly a in shop $\mathrm{s}$

$S L_{m, a, s}=$ Service life of the material $\mathrm{m}$ in assembly a in shop s

$R F_{S} \quad=$ Refurbishment frequency of shop $\mathrm{s}$

However, RR can also be represented as the refurbishment frequency (RF) of the shops in shopping centre.

A similar sequence of calculations is used to generate LCMC values of different assembly combinations for archetypal shopping centre scenarios. However, unlike recurrent embodied energy, recurrent material cost is discounted to present value to 
account for time value of money. Once the calculations are fully performed, the combinations of assemblies responsible for minimum LCEE and minimum LCMC independently are recorded achieving objective functions 1 and 2 . Then the model executes the optimization process to identify combinations which lead to minimum tradeoff of LCEE and LCMC achieving the third objective function. However, this paper does not deliver particulars of the optimization process.

\section{Discussion and conclusion}

This paper aimed in discussing the process of developing a mathematical model using OOP to investigate the combinations of building assemblies with optimal LCEE and LCMC for sub-regional shopping centre construction in Australia. The research problem is detailed in the beginning to provide the reader a clear understanding of the system and what is required of the model. Application of OOP to resolve the research problem is demonstrated in section 3. Assessment of LCEE of the archetypal subregional shopping centre is exhibited as a sample. The research by $[36,37]$ are pioneering in the area of life cycle energy assessments in residential buildings, which are used as fundamentals for the model. The automated calculations of building elements make preparation of bills of quantities (BOQ) of the shops an effortless process. Defining parametric shop designs based on basic building geometries (length, width, height and span) to prepare BOQ allows future expansions to the model regarding design upgrades (changes to shopping centre layout, shop designs). The developed system is primarily focused on shopping centres which is currently an underresearched area. Yet, it can be used to assess life cycle energy and cost impacts of other property types with some modifications and alterations to databases and programming. Furthermore, the model can be used in future scenarios of more advanced materials and assemblies with updates to Materials and Assemblies databases.

However, the model developed, and the results are subject to limitations due to uncertainty and variability in the data. Notably, the LCEE quantification process used in the model experience several limitations due to use of hybrid embodied energy coefficients [17], calculation of the non-material energy inputs (following the equations developed by [25]) and the algorithms used to calculate material replacement rate. Additionally, the model performs LCEE and LCMC calculations for materials and assemblies in the databases developed based on empirical data and research data for innovative materials and assemblies. Even though assembly-assembly compatibility matrix and shop-assembly compatibility matrix are used to address design, structural and material constraints the results are subject to limitations in reliability and uncertainty for future scenarios. Nevertheless, the model is comparatively comprehensive and provide reliable results, overcoming the drawbacks of previous life cycle energy assessment models. Hence, this approach can be applied in similar optimization problems in the built environment. Even though this paper does not review the optimization process, the detailed presentation of development of OOP structure provides proper insight to the mathematical core for future applications. 


\section{References}

1. Jones Lang LaSalle. Australian shopping centre investment review \& outlook. 2019.

2. Juaidi A, AlFaris F, Montoya FG, Manzano-Agugliaro F. Energy benchmarking for shopping centers in Gulf Coast region. Energy Policy. 2016;91:247-55.

3. Haase M, Skeie KS, Woods R. The Key Drivers for Energy Retrofitting of European Shopping Centres. Energy Procedia. 2015;78:2298-303.

4. Braslavsky JH, Wall JR, Reedman LJ. Optimal distributed energy resources and the cost of reduced greenhouse gas emissions in a large retail shopping centre. Applied Energy. 2015;155:120-30.

5. Coleman P. Shopping Environments : Evolution, Planning and Design: Jordan Hill : Taylor and Francis, 2007.; 2007.

6. Scott KM. Shopping center tenant coordination. 2006.

7. Wakefield KL, Baker J. Excitement at the mall: Determinants and effects on shopping response. Journal of Retailing. 1998;74(4):515-39.

8. Holtzhausen HJ. Embodied energy and its impact on architectural decisions. 2007;II:37785 .

9. Fieldson R, Rai D. An assessment of carbon emissions from retail fit-out in the United Kingdom. Journal of Retail \& Leisure Property. 2009;8(4):243-58.

10. Lewry AJ, Suttie, E. Ecoshopping: energy efficient \& cost competitive retrofitting solutions for retail buildings. Romanian Journal of Civil Engineering. 2015;6(1):87-100.

11. Climateworks Australia. Low Carbon Growth Plan for Australia retail sector summary report. 2011.

12. Thompson B. Green retail: Retailer strategies for surviving the sustainability storm. Journal of Retail and Leisure Property. 2007;6(4):281-6.

13. Kocaili BE. Evolution of shopping malls: Recent trends and the question of regeneration. 2010.

14. Bansal D, Singh R, Sawhney RL. Effect of construction materials on embodied energy and cost of buildings - A case study of residential houses in India up to $60 \mathrm{~m} 2$ of plinth area. Energy and Buildings. 2014;69:260-6.

15. Castro-Lacouture D, Sefair JA, Flórez L, Medaglia AL. Optimization model for the selection of materials using a LEED-based green building rating system in Colombia. Building and Environment. 2009;44(6):1162-70.

16. Yudelson J. Sustainable retail development. [electronic resource] : new success strategies: Dordrecht ; New York : Springer ; [New York] : International Council of Shopping Centers, c2009.; 2009.

17. Crawford RH, Bontinck P-A, Stephan A, Wiedmann T, Yu M. Hybrid life cycle inventory methods - A review. Journal of Cleaner Production. 2018;172:1273-88.

18. Ramesh T, Prakash R, Shukla KK. Life cycle energy analysis of buildings: An overview. Energy and Buildings. 2010;42(10):1592-600.

19. Máté K. Remediating Shopping Centres for Sustainability. 2013.

20. Inyim P, Zhu Y, Orabi W. Analysis of time, cost, and environmental impact relationships at the building-material level. Journal of Management in Engineering. 2016(4):4016005.

21. Shopping Centre Council of Australia. Shopping Centre Redevelopment. 2017.

22. Aktas GG. Sustainable Approaches in Shopping Center Public Interiors: Lighting and Finishing Materials. 2011:183-7.

23. Jiao Y, Lloyd CR, Wakes SJ. The relationship between total embodied energy and cost of commercial buildings. Energy and Buildings. 2012;52:20-7. 
24. Akadiri PO. Understanding barriers affecting the selection of sustainable materials in building projects. Journal of Building Engineering. 2015;4:86-93.

25. Crawford RH. Life cycle assessment in the built environment: Abingdon, Oxon : Spon Press, 2011.; 2011.

26. Seo S, Tucker SN, Ambrose MD. Selection of sustainable building material using LCADesign tool. 2007.

27. CBRE Research. Sub-Regional Shopping Centres : A case of middle child syndrome. Report. Australia: CBRE RESEARCH; 2018 November 2018.

28. Jones Lang LaSalle. Australian shopping centre investment review \& outlook. 2017.

29. Lott SF, Fatouhi D. Mastering object-oriented Python : grasp the intricacies of objectoriented programming in Python in order to efficiency build powerful real-world applications: Packt Publishing; 2014.

30. Tokoro M, Pareschi R. Object-oriented programming : 8th European Conference, ECOOP '94, Bologna, Italy, July 4-8, 1994 : proceedings: Springer-Verlag; 1994.

31. Phillips D. Python 3 object oriented programming. [electronic resource] : harness the power of Python 3 objects: Birmingham, U.K. : Packt Open Source, 2010.; 2010.

32. Stanger N, Pascoe R. Exploiting the advantages of object oriented programming in the implementation of a database design environment. 1997. p. 525.

33. Python Software Foundation. Python language reference, version 2.7. Python Software Foundation Wilmington, DE; 2010.

34. The Australian Institute of Quantity Surveyors. Australian cost management manual: Canberra, A.C.T. : Australian Institute of Quantity Surveyors, 2000-2008.; 2000.

35. International Council of Shopping Centres. Dictionary of shopping centre terms. International Council of Shopping Centers; 2005. p. 63-4.

36. Stephan A, Crawford RH. The relationship between house size and life cycle energy demand: Implications for energy efficiency regulations for buildings. Energy. 2016:1158.

37. Stephan A, Stephan L. Reducing the total life cycle energy demand of recent residential buildings in Lebanon. Energy. 2014;74:618-37 